\title{
Mesleki ve Teknik Anadolu Liseleri Yöneticilerinin Teknik Liderlik Becerilerinin Geliştirilmesi*
}

\author{
The Development of Technical Leadership Skills of \\ Vocational and Technical Anatolian High School Principals
}

\author{
Gökçe ÖZDEMİ**, Sevilay ŞAHIN***
}

\begin{abstract}
Öz: Bu araştırmanın amacı, Mesleki ve Teknik Anadolu Liselerinde görev yapan okul yöneticilerinin teknik liderlik becerilerinin geliştirilmesi için bir eğitime ihtiyaç olup olmadığının, eğer eğitime ihtiyaç varsa böyle bir eğitimin nasıl yapılandırılması gerektiğinin yönetici, öğretmen ve eğitim yönetimi alan uzmanları görüşlerine göre belirlenmesidir. Araştırma nitel araştırma yöntemlerinden durum çalışması deseninde yapılmış olup, araştırma verileri yarı yapılandırılmış görüşme formları ile toplanmıştır. Veriler içerik analiz yöntemi ile analiz edilmiştir. Araştırma sonucunda, mesleki ve teknik eğitim yöneticilerinin teknik liderlik becerilerinin geliştirilmesine katkı sağlayacak bir eğitime ihtiyaç olduğu tespit edilmiştir. Eğitimin, mesleki ve teknik eğitimin felsefesine ve var oluş misyonuna uygun dersleri kapsaması ve önce teorik bilgilerin verildiği, eğitim-öğretim süreci içerisinde ise pratik uygulamaların yapıldığı eğitim şeklinde verilmesi gerektiği sonucuna ulaşılmıştır. Ayrıca eğitimin değerlendirme aşamasında eğitimi veren uzmanların ve eğitimden fayda sağlayıcıların birlikte değerlendirme yapması gerektiği ve eğitimden beklenen faydanın sağlanabilmesi için eğitimlerin, alan akademisyenleri, deneyimli müdürler, sektör uzmanları ve $\mathrm{AB}$ temsilcileri işbirliği ile verilmesi gerektiği sonucuna varılmıştır.
\end{abstract}

Anahtar Kelimeler: Mesleki ve teknik eğitim, teknik liderlik becerisi, eğitim

\begin{abstract}
The aim of this study was to determine whether it is a requirement to create a training program for the technical leadership skills of the principals working at Vocational and Technical Anatolian High Schools, and if it is needed, how such a training program should be structured according to the opinions of administrators, teachers and the experts in the field of educational administration. The study was designed in a case study pattern, which is one of qualitative research methodology and the data were collected through a semi-structured interview forms. The data were analyzed by content analysis method. As a result of the study, it was ascertained that there is a necessity for a training program that will contribute to the development of technical leadership skills of vocational and technical school administrators. It was concluded that the program should include the courses that are appropriate to the philosophy and raison d'être of vocational and technical education and theoretical knowledge should be followed by practical applications during the educational process. In addition, it was deduced that the educators and stakeholders of the training should evaluate together during the evaluation phase, and the program should be supplied in cooperation with the academicians, experienced principals, sector experts and EU representatives to yield the anticipated benefits.
\end{abstract}

Keywords: Vocational and technical education, technical leadership skills, training

\section{Giriş}

Sürdürülebilir ekonomik ve sosyal gelişimlerin sağlanması ve rekabet edilebilirliğin arttırılabilmesi için ülkenin ihtiyaç duyduğu mesleki bilgi ve becerilere sahip bireylerin yetiştirebilmesinin temel dayanağı mesleki ve teknik eğitimdir. Küreselleşme ile birlikte teknolojik alanlarda yaşanan hızlı gelişmeler ve hizmet sektörünün ekonomideki payının artışı

\footnotetext{
* Bu çalışmanın bir kısmı 05 - 07 Kasım 2015 tarihlerinde düzenlenen "VI. Eğitim Yönetimi Formu”nda sözlü bildiri olarak sunulmuş ve birinci yazarın doktora tezinin bir kısmından türetilmiştir.

** Dr. Öğretim Üyesi, Gaziantep Üniversitesi, Nizip Eğitim Fakültesi, Gaziantep-Türkiye, ORCID: 0000-0002-26086004, e-posta: gozdemir@gantep.edu.tr

*** Doç. Dr., Gaziantep Üniversitesi, Eğitim Fakültesi, Gaziantep-Türkiye, ORCID: 0000-0002-7140-821X, e-posta: ssahin@gantep.edu.tr
} 
sektörel ihtiyaçlara cevap verebilecek nitelikte iş gücüne olan talebi artırırken aynı zamanda bu işgücünün sahip olması gereken becerilerde de köklü değişimlere yol açmıştır. Bu eğilimin gelecekte de devam etmesi beklenmektedir. Genel olarak, belirli bir mesleğin gerektirdiği nitelikleri kazandırmayı amaçlayan mesleki eğitim; bireyin iş yaşamına ilişkin mesleki bilgi, beceri ve alışkanlıkları kazandıran ve bireyin sahip olduğu beceri ve yetenekleri farklı yönlerden geliştiren bir eğitim süreci olarak tanımlanırken (Karaçam, 1996), teknik eğitim ise; üst düzey fen ve matematik bilgisine sahip ve bu bilgileri uygulayabilme becerisi kazanmış mühendislik, tarım, sağlık, ticaret, beslenme gibi her alanda yer alabilecek insanı yetiştiren eğitim olarak ifade edilmektedir (Ünsür, 1998, Akt. Ünlüeser, 2007, s. 13). Bu çerçevede, mesleki ve teknik eğitim, gerek bireysel, sosyal ve kültürel gerekse ulusal gereksinimler için bir ülkenin eğitim sisteminin en vazgeçilmez öğelerinden birisi olarak ülkenin ekonomik ve toplumsal gelişmişliğini sağlamaktadır (Anapa, 2008, s. 5). Buradan hareketle, iş gücünün niteliğinin arttırılması ve bilgi toplumunun ihtiyaçlarına cevap verebilecek esnek yapıların oluşturulabilmesi için bu sistemin uygulayıcısı olan iyi örgütlenmiş mesleki ve teknik eğitim kurumlarına ve bu kurumları iyi yönetebilecek yöneticilere ihtiyaç vardır. Ülkelerin ihtiyaç duyduğu rekabetçi ekonomiyi destekleyecek nitelikli insan gücünü yetiştirme görevi öncelikli olarak meslekî ve teknik eğitim kurumlarının işlevi olduğundan, bu kurum yöneticilerinin diğer eğitim kurumları yöneticilerinden farklı becerilere sahip olmaları gerektiği ifade edilebilir. Çünkü türü ve kademesi ne olursa olsun, bir okulun başarısında en büyük pay okul müdürüne aittir (Austin ve Holowenzak, 1985; Arnn ve Mangieri, 1988; Balc1, 2001; Buluç, 2009; Levine ve Lezotte, 1990) ve okulla ilgili her boyut mutlaka okul müdürüyle bağlantılıdır. Gürbüz ve diğerlerinin (2013, s. 170) da belirttiği üzere mesleki ve teknik eğitim okul liderlerinin başarılı olabilmeleri için sadece öğrencinin akademik başarısını arttırma üzerine odaklanmamaları, aynı zamanda eğitim-öğretim ortamının etkililiğini artırmak ve beceri gelişimini desteklemek için gerekli donanımsal kaynakları temin etmeleri, derse hazırlık aşamasında öğretmeni desteklemeleri, okul içerisinde sağlıklı bir iletişimin kurulabilmesi bakımından okul içi ve okul dışı tüm paydaşlarla işbirliği bağları kurmaları, öğrencilerin öğrenme becerilerinin gelişmesi noktasında gerekli ortamları oluşturma gibi önemli görevleri üstlenmeleri gerekmektedir. Bütün bunlar da mesleki ve teknik eğitim yöneticisinin hem yaptığı işin teknik yönüyle hem de kurum içi ve kurum dışı tüm paydaşlarla nasıl etkili bir şekilde birlikte çalışacağı noktasında teknik liderlik becerilere sahip olması gerektiğini açıkça göstermektedir.

Teknik liderlik, genel olarak, örgütsel yapı içerisinde meydana gelen veya gelebilecek olan sorunlarla ilgili çözümler üretmek için mevcut paradigmalara karşı uygulanan değişimleri yönetme; yani bir örgütün alışılagelmiş olan değer, inanç ve kültür yapılarını örgütsel bir değişime uyumlu hale getirebilme olarak tanımlanmaktadır (Cohen, Manion ve Morrison, 2003; Daly ve Chrıspeels, 2008; Maxwell ve Covey, 2007). Okul bazında ele alındığında ise, öğrencinin akademik başarısının artırımı, okul gelişimi ve öğretmen mesleki gelişiminde okul yöneticilerinin teknik ve uyumsal liderlik özellikleri üzerine vurgu yapılmaktadır (Daly ve Chrıspeels, 2008). Bu özellikler Kochamba'ya (1996, s. 29) göre prosedürlerdeki, yöntemlerdeki ve eğitim tekniklerindeki (finans, muhasebe, bakım onarım, programlama ve satın alma) yeterliği; Meadows'a (2007) göre ise örgütsel hedeflere ulaşmada alınan sorumlulukları yerine getirmek için gerekli olan kabiliyetleri ve yeterlikleri kapsamaktadır. Mesleki ve teknik eğitim okul yöneticileri literatüründe teknik liderlik, mesleki ve teknik eğitim okul yöneticilerine özgü olan, onları diğer eğitim kurumları yöneticilerinden ayıran ve mesleki ve teknik eğitimin felsefesine ve var oluş misyonuna uygun liderlik becerileri olarak tanımlanmaktadır. Bu bağlamda, Coates ve diğerleri (2010) meslek okulu yöneticilerinin üst düzey yönetici olduklarını ve onların özellikle; toplumsal bütünleşme, politika oluşturma, paydaşlar ile etkili iletişim ağ 1 oluşturma becerisine sahip, örgütsel gelişim ve değişim konularında eğitimli, kalite güvenceyi önemseyen kimseler olması gerektiğini belirtmişlerdir. Alanda yapılan çalışmalar 1şığında, mesleki ve teknik eğitim okulları yöneticilerinin, genel ortaöğretim okulları yöneticilerden farklı olarak, sahip olmaları gereken teknik liderlik becerileri; pedagojik ve sosyal beceriler, yönetimsel beceriler ve mesleki beceriler olarak üç alt başlık altında incelenmiştir (Özdemir, 2015). Pedagojik ve sosyal beceriler, öğretmen ve öğrenciler için öğretme ve öğrenmeyi etkileyen faktörlerin belirlenmesi ve 
geliştirilmesi, teorik bilgi ile pratik uygulamaların bütünleştirilmesi ve eğitimden beklenen verimliliğinin artırılması gibi faaliyetleri kapsamaktadır. Yönetimsel beceriler, mesleki ve teknik eğitimin kendine özgü yapısı içerisindeki; okul işletmeciliği, insan kaynakları kullanımı, kalite güvence, denetim, danışmanlık, öğretimsel süreçleri kolaylaştırma ve planlama yapma gibi liderlik davranışlarını kapsamaktadır. Mesleki beceriler ise, mesleki ve teknik eğitim okul liderlerinin, iş yeri eğitimlerinin başarıyla gerçekleşmesi ve örgütsel gelişimi sağlama adına yaptığı faaliyetlerdir.

Ülke ekonomilerinin geliştirilmesinde ve artan rekabet ortamında üretilen mal ve hizmetlerin kalitesinin arttırılmasında mesleki ve teknik eğitim okullarına önemli görevler düşmektedir. Özellikle, beşeri kaynakların sektörel ihtiyaçlara göre yetiştirilmesi için mesleki ve teknik eğitimin; öğretim metotlarını güncelleme, öğretmenlerini ve kurum yöneticilerini güncel gelişmeler 1şığında yenileştirme ve yetiştirme ihtiyacı ortaya çıkmaktadır. Ayrıca mesleki ve teknik eğitim yöneticilerinin yeterliklerine ilişkin yapılan çalışmalarda (A ğaoğlu, 2012; Altınkurt, 2007; Cedefop, 2008, 2009, 2010, 2011, 2012, 2013; NCVER, 2001, 2003, 2007, 2012; Sadıkoğlu, 2007) göstermektedir ki bu kurum yöneticilerinin yukarıda bahsedilen gelişmeleri takip etme ve kendilerini geliştirme konusunda yeterlikleri düşük düzeydedir. Benzer şekilde Hsiao, Chen ve Yang (2008), çalışmalarında meslek lisesi müdürlerinin müfredat lideri, savunucu, yönlendirici, koordinatör, birleştirici, danışman, izleyici, koordinasyon sağlayıcı, vizyon belirleyici, kaynak sağlayıcı, uygulama sorunlarını çözücü ve geri bildirim sağlayıcısı olmaları gerektiği sonucuna ulaşmışlardır. Mesleki ve teknik eğitim çok uzun zamandır üzerinde çokça konuşulan ancak bu alanda yaşanılan sorunların çözümü noktasında istenilen sonuçlara ulaşılmayan tam bir eğitim sorunsalıdır. Meslek liselerindeki, program çeşitliliğinin fazla olması, eğitimin ağırlıklı olarak okul-sanayi işbirliğinde yürütülmesi ve teknoloji kullanımının ön planda olması nedeniyle hem yöneticilerin hem de öğretmenlerin yeterlikleri ve bu yeterlikleri kullanılabilme becerileri sık sık dile getirilmektedir. Bunun içindir ki mesleki ve teknik eğitim niteliğinin arttırılarak gerek çalışan personelin, gerekse öğrencilerin ve okulun diğer paydaşlarının beklentilerinin en iyi şekilde karşılanabilmesi için bu okul yöneticilerinin sahip olması gereken teknik boyuttaki liderlik becerilerin geliştirilmesi ve bu becerilerin kazandırılması için neler yapılması gerektiği son derece önemli hale gelmektedir. Bu bağlamda araştırmanın amac1, MTE yöneticilerinin teknik liderlik becerilerinin geliştirilmesine yönelik bir eğitime ihtiyaç olup olmadığının, eğer eğitime ihtiyaç varsa, bu becerileri geliştirmek için tasarlanacak eğitimin; dersler, süre, değerlendirme ve eğitimi verecek kişiler boyutlarında nasıl yapılandırılması gerektiğinin belirlenmesidir. $\mathrm{Bu}$ amaca bağlı olarak araştırmada şu alt problemlere cevap aranmıştır:

1. Teknik liderlik becerilerin geliştirilmesindeki, eğitim ihtiyacına yönelik öğretmen ve yönetici görüşleri nelerdir?

2. İhtiyaç duyulan eğitimin; hangi derslerden oluşması, süre ve değerlendirme boyutlarının nasıl olması gerektiğine yönelik yönetici ve öğretmen görüşleri nelerdir?

3. Teknik liderlik becerileri geliştirme eğitiminde yer alabilecek; derslere, eğitimin süresine, eğitimin veriliş şekline ve eğitimin kimler tarafindan verilmesi gerektiğine yönelik eğitim yönetimi alan uzmanlarının görüşleri nelerdir?

\section{Yöntem}

Araştırma nitel araştırma türündedir. Araştırmada nitel araştırma desenlerinden araştırmanın doğasına uygun olan durum çalışması (case study) deseni kullanılmıştır. Millan (2000), durum çalışmalarını bir ya da daha fazla olayın, ortamın, programın, sosyal grubun ya da diğer birbirine bağlı sistemlerin derinlemesine incelendiği yöntem olarak tanımlamaktadır (Akt. Büyüköztürk Çakmak, Akgün, Karadeniz, ve Demirel, 2013, s. 249). Bu araştırmada da durum temelli bir yaklaşım benimsenerek, çapraz doğrulama yapmak için farklı katılımcı gruplardan görüşler alınmıştır. 


\section{Çalışma grubu}

Araştırmanın çalışma grubunu Gaziantep ili Şahinbey ve Şehitkamil ilçelerinde yer alan Mesleki ve Teknik Eğitim Anadolu Liselerinde çalışan okul müdürleri/müdür yardımcıları, öğretmenleri ve eğitim yönetimi alan uzmanları oluşturmaktadır. Çalışma grupları amaçlı örnekleme yöntemlerinden maksimum çeşitlik ve ölçüt örneklemesi yöntemleri kullanılarak belirlenmiştir. Amaçlı örnekleme yöntemi, genelleme kaygısı güdülmeksizin mümkün olduğunca hedeflenen çalışma grubunda olması muhtemel bütün çeşitliliği, zenginliği, farklılığı ve aykırılığı temsil edecek bütüncül bir resmin elde edilmeye çalışıldığı bir örnekleme yöntemidir (Karataş, 2015; Yıldırım ve Şimşek, 2013). Öğretmen ve yönetici katılımcıların yer aldığı çalışma grubunu Gaziantep ili Şahinbey ve Şehitkamil ilçelerinde bulunan 3'ü şehir merkezinde, 3'ü de kırsalda yer alan toplam 6 MTE okulundaki 30 öğretmen, 18 okul müdürü/müdür yardımcıları oluşturmaktadır. Okullar; kız meslek, endüstri meslek ve ticaret meslek liseleri arasından kuruluş yılları en eski olanlar ölçüt alınarak belirlenmiştir. Eğitim yönetimi alan uzmanları ise mesleki ve teknik eğitim yöneticileri üzerine çalışmalar yapmış olma ölçütünü karşılayan ve araştırmaya gönüllü olarak katılan 5 öğretim üyesinden oluşmaktadır. Yönetici katılımcıların, 12'si $(\% 66,7)$ erkek, 6's1 (\%33,3) kadın, 6'sı okul müdürü $(\% 66,7), 12$ 'si $(\% 33,3)$ müdür yardımcısıdır, 11 'nin $(\% 61,1)$ mesleki branş1 kültür, 7'sinin $(\% 38,9)$ ise meslektir. Yöneticilerin 11'inin $(\% 61,1)$ yöneticilik deneyimi $2-5$ yıl, 5'nin $(\% 27,8) 6$ y1l ve üzeri, 2'sinin $(\% 11,1)$ ise 1 yıldır. Öğretmen katılımcıların, 18'i (\%60) kadın, 12'si (\%40) erkek, 12'sinin (\%40) kurumdaki çalışma süresi 25 y1l, 11'inin (\%36,7) 1 yıl, 7'sinin (\%23,3) ise 6 y1l ve üzeridir. Ayrıca öğretmenler 20 farklı branşa sahiptirler. Eğitim yönetimi alan uzmanlarının ise, 3’ü (\%60) profesör, 2'si (\%40) doçent unvanına sahiptir.

\section{Veri toplama araçları}

Veriler iki farklı görüşme formu ile toplanmıştır. Formların birincisi, öğretmen ve yönetici katılımcılar için hazırlanmış yarı yapılandırılmış görüşme formudur. Öğretmen ve yönetici katılımcılar için hazırlanan görüşme formunda; eğitim ihtiyacı, eğitimde olabilecek dersler, eğitimin süresi ve eğitimin değerlendirmesi boyutlarına yönelik toplam 4 soru yer almaktadır. Eğitim yönetimi alan uzmanlarının görüşlerini belirlemeye yönelik hazırlanan görüşme formu ise katılımc1 grup içerisinde yer alan öğretmen ve yönetici görüşleri analiz edildikten sonra hazırlanmıştır. Hazırlanan yarı yapılandırılmış görüşme formunda, yönetici ve öğretmenlerin derslere yönelik olan görüşleri, orta öğretim yönetmeliği, Singapur hükümetinin mesleki ve teknik eğitim yöneticisi eğitim programı ve 2012 METEK strateji çalışma grubunun "Liderlik ve Finansman" isimli çalıştay sonuçları baz alınarak oluşturulmuş, dersler ve kazanımlarına yönelik 1 soru, eğitimin süresi, eğitimin veriliş şekli ve eğitimin kimler tarafından verilmesi gerektiğine yönelik 3 soru olmak üzere toplamda 4 soru yer almaktadır. Hazırlanan formların, görüşmeler öncesi uzman görüşüne başvurularak gerekli düzeltmeleri yapılmıştır.

\section{Verilerin analizi}

Verilerin analizinde içerik analizi yöntemi kullanılmıştır. Öncelikle formlardan elde edilen veriler Atlas.ti nitel veri analiz programına aktarılarak, birbirleri ile ilişkili kavramlardan kodlar oluşturulmuş daha sonra ise her bir kod araştırmacılar tarafından görüşme soruları esas alınarak belirlenmiş temalar ve alt temalar altına yerleştirilmiştir. Yıldırım ve Şimşek (2013), yapılan araştırmanın temelini oluşturan bir kuram ya da kavramsal çerçeve olduğunda veriler toplanmadan önce bir tema, alt tema ve kod listesi çıkarmanın mümkün olabileceğini ve verilerin analizi esnasında ortaya çıkan yeni tema ve kodların önceden oluşturulan listeye eklenebileceğini ifade etmektedirler.

Araştırmanın iç geçerliğini arttırmak için görüşmeler öncesi katılımcılara araştırmaya ilişkin bilgiler verilmiştir. Böylelikle katılımcı gruplardan daha derinlemesine ve sağlıklı veri toplanmaya çalışılmıştır. Araştırmanın iç geçerliğini artırmak amacıyla başvurulan son yöntem katılımcı teyididir. Buna göre, veriler toplandıktan sonra bilgisayar ortamında yazıya aktarılmış ve katılımcılara, aktarılanların kendi algılarını yansıtıp yansıtmadığı teyit ettirilmiştir. 
Araştırmada, dış geçerliği artırmak amacıyla, belirlenen kodlara ilişkin katılımcıların her birine bir kod verilerek (Ö1, Y3, Ö5, Y8, K1, K3 vb.), doğrudan alıntılara yer verilmiştir. Bunun yanı sıra veri toplanılan okullarda, katılımcıların farklı bölümlerden olmalarına ve öğretmenlerin yanı sıra yöneticilerden de görüş alınarak, farklı kaynaklardan veri toplama yoluna gidilmiştir.

Ayrıca iç güvenirliği artırmak için veriler, iki farklı araştırmacı tarafından kodlanmış ve bağımsız kodlayıcılar arası tutarlılık hesaplanmıştır. Bağımsız kodlayıcıların sonuçlarına göre, oluşturulan temalar, alt temalar ve kodlar arası görüss birliği ve görüş ayrı̆̆ 1 olan kısımlar belirlenmiştir. Miles ve Huberman (1994) tarafından belirtilen formül yardımıyla da güvenirlik hesaplaması yapılmıştır. Yapılan hesaplama sonunda, veri analizindeki kodlamaların güvenirliği \% 94 olarak bulunmuştur. Miles ve Huberman'1n (1994, s. 64), "Hesaplanan sonucun \% 90'1 geçmesi halinde, veri toplama aracı güvenilir olarak kabul edilir." ifadesinden hareketle yapılan analizin güvenilir sonuçlar verdiğini söylenebilir.

Yıldırım ve Şimşek (2013), araştırmada dış güvenirliğin sağlanması amacıyla veri toplama ve analiz yöntemleri ile ilgili ayrıntılı açıklamalara yer verilmesi gerektiğini belirtmiş̧lerdir. $\mathrm{Bu}$ bağlamda, verilerin nasıl toplandığ 1 ve analiz edildiği ile ilgili detaylı açıklamalara yer verilmiştir.

\section{Bulgular}

MTE yöneticilerinin, teknik liderlik becerilerinin geliştirilmesi için bir eğitime gereksinim olup olmadığına yönelik öğretmen ve yöneticilerle görüşmeler yapılmıştır. Elde edilen bulgular sonucunda, öğretmenlerin ve yöneticilerin büyük bir çoğunluğunun mesleki ve teknik eğitimde, sürdürülebilir gelişimin sağlanması için teknik liderlik becerilerin geliştirilmesinde yöneticilerin eğitim almaya ihtiyacı olduğunu $(n=27, n=16)$, katılımcıların çok az bir kısmının ise eğitime ihtiyaç olmadığını $(n=3, n=2)$ belirttikleri sonucuna ulaşılmıştır. Katılımcıların bazılarının görüşleri şunlardır:

"Mesleki ve Teknik ĕgitimde sürdürülebilirlik için hayat boyu ögrenmenin öneminden bahsediliyor hep, bu bağlamda yaklaşırsak, eğitim alınsın hatta uygulamalı eğitim yani uygulamanın gözlemlendiği hem hizmet öncesi hem de hizmet içi eğitimler olsun." (Ö4)

"Kesinlikle eğitim alınması gerektiğine inanıyorum. Bizler her zaman için alanın bizden beklediklerini karşılayamıyoruz, bu noktadaki eksikliklerimizi gidermek ve okulun sadece bürokratik yapısını yürütmeye çalışmaktan ziyade okulun amaçlarını gerçekleştirebilecek liderlik becerilerine sahip olmamı gerekiyor." (Y1)

"Eğitime ihtiyaç yok çünkü bizim yöneticilerimizin eğitime değil, okulu daha iyi şartlara getirebilmek, eğitim-ögretim kalitesini arttırabilmek amaçlı desteğe ihtiyacı var diye düşünüyorum." (Ö3).

"Eğitime gerek yok bence kişi isterse kendini geliş̧tirebilir." (Y3)

İkinci alt problemde, öğretmen ve yöneticilere teknik liderlik becerilerin geliştirilmesinde ihtiyaç duyulan bir eğitimde yer alması gereken derslere, eğitimin süresine ve eğitimin değerlendirme boyutlarına ilişkin sorular sorulmuştur. Öğretmen ve yöneticilerin bu alt probleme yönelik görüşleri Tablo 1'de yer almaktadır. 
Tablo 1.

Öğretmen ve Yöneticilerin Teknik Liderlik Becerilerin Geliştirilmesi Eğitimine Yönelik Görüşleri

\begin{tabular}{|c|c|c|c|c|c|}
\hline Tema & Alt tema & Kodlar (Öğretmen) & $\mathrm{n}$ & Kodlar (Yönetici) & $\mathrm{n}$ \\
\hline \multirow{27}{*}{ 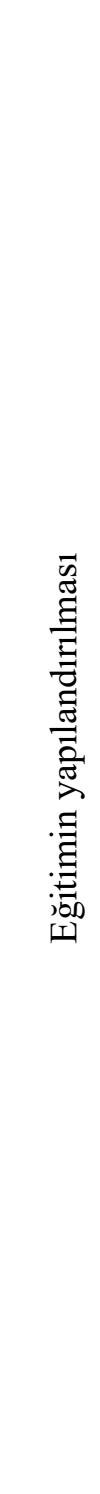 } & \multirow{14}{*}{ 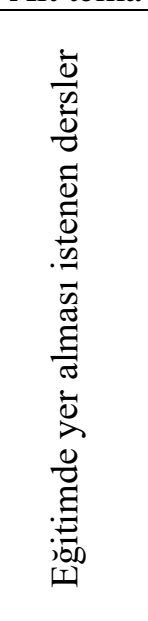 } & $\checkmark$ Liderlik & 11 & $\checkmark$ İletisim & 7 \\
\hline & & $\checkmark$ İletisim & 11 & $\checkmark$ Mesleki ve Teknik & 6 \\
\hline & & $\checkmark$ Veri Toplama ve Analiz & 7 & Eğitimi Tanıma & \\
\hline & & Yapma & & $\checkmark$ Liderlik & 5 \\
\hline & & $\checkmark$ Mesleki ve Teknik Eğitimi & 6 & $\checkmark$ Kariyer Danışmanlığı & 3 \\
\hline & & Tanıma & & $\checkmark$ Zaman Yönetimi & 2 \\
\hline & & $\checkmark$ Stratejik Planlama & 6 & $\checkmark$ Veri Toplama ve & 2 \\
\hline & & $\checkmark$ Bütçe Yönetimi & 3 & Analiz Yapma & \\
\hline & & $\checkmark$ Okul Hukuku & 3 & $\checkmark$ Bütçe Yönetimi & 2 \\
\hline & & $\checkmark$ Risk Yönetimi & 3 & $\checkmark$ Stratejik Planlama & 2 \\
\hline & & $\checkmark$ Kaynak Yönetimi & 2 & $\checkmark$ Değişim Yönetimi & 1 \\
\hline & & $\checkmark$ Değişim Yönetimi & 2 & $\checkmark$ Teknoloji Kullanımı & 1 \\
\hline & & $\checkmark$ Kariyer Danışmanlığ1 & 2 & $\checkmark$ Kaynak Yönetimi & \\
\hline & & $\checkmark$ Zaman Yönetimi & 1 & & \\
\hline & & $\begin{array}{l}\checkmark \text { Dersin içeriğine göre } \\
\text { düzenlenmelidir }\end{array}$ & 9 & $\begin{array}{c}\checkmark \text { Dersin içeriğine göre } \\
\text { düzenlenmelidir }\end{array}$ & 6 \\
\hline & $\bar{w}$ & $\checkmark$ Devamlılık arz etmelidir & 6 & $\checkmark$ Devamlilık arz & 4 \\
\hline & $:$ & $\checkmark$ Alan uzmanları karar & 5 & etmelidir & \\
\hline &.$\nexists$ & vermelidir & & $\checkmark$ Bir eğitim-öğretim & 2 \\
\hline & $\Xi$ & $\checkmark$ Bir eğitim-öğretim yılı & 4 & dönemi olmalıdır & 0 \\
\hline & 告 & $\checkmark$ Bir eğitim-öğretim dönemi & 2 & olmalıdır & \\
\hline & & olmalıdır & & $\checkmark 10$ günlük olmalıdır & 1 \\
\hline & & $\checkmark$ Bir hafta olmalıdır & 1 & $\checkmark$ Bir haftalık olmalıdır & 1 \\
\hline & & $\begin{array}{l}\checkmark \text { Anketlerle paydaş } \\
\text { değerlendirmesi }\end{array}$ & 14 & $\begin{array}{c}\text { Anketlerle paydaş } \\
\text { değerlendirmesi }\end{array}$ & 5 \\
\hline & $=\stackrel{\vec{\otimes}}{=}$ & $\begin{array}{l}\checkmark \text { Performans kriterlerine } \\
\text { göre değerlendirme }\end{array}$ & 5 & $\begin{array}{l}\checkmark \text { Alan uzmanlarına göre } \\
\text { değerlendirme }\end{array}$ & 2 \\
\hline & 䓪 & $\begin{array}{l}\checkmark \text { İzleme, değerlendirme ve } \\
\text { geri dönüt verme }\end{array}$ & 5 & $\begin{array}{c}\checkmark \text { Performans kriterlerine } \\
\text { göre değerlendirme }\end{array}$ & 2 \\
\hline & 되 $\overline{\bar{v}}$ & $\begin{array}{l}\checkmark \text { Alan uzmanlarına göre } \\
\text { değerlendirme }\end{array}$ & 3 & $\begin{array}{l}\checkmark \text { İzleme, değerlendirme } \\
\text { ve geri dönüt verme }\end{array}$ & 2 \\
\hline & & & & $\begin{array}{l}\checkmark \text { Değerlendirmeye gerek } \\
\text { yok }\end{array}$ & 1 \\
\hline
\end{tabular}

Tablo 1. incelendiğinde, eğitimde hangi dersler yer almalıdır? Sorusuna her iki katılımcı grupta, mesleki ve teknik eğitimde kalite ve başarıyı hedef alan bir teknik liderlik beceri eğitiminin olması gerektiğini belirtmişlerdir. Katılımcılar, liderliğin önemine dikkat çekerek; Liderlik ( $n=11, n=5)$, İletişim $(n=11, n=7)$, Veri toplama ve Analiz yapma $(n=7, n=2)$, Mesleki ve Teknik Eğitimi Tanıma ( $(n=6, n=6)$, Stratejik Planlama ( $(n=6, n=2)$, Bütçe Yönetimi $(n=3, n=2)$, Kaynak Yönetimi ( $(n=2, n=1)$, Değișim Yönetimi $(n=2, n=1)$, Kariyer Danıșmanlığ $(n=2, n=3)$, Zaman Yönetimi $(n=1, n=2)$ gibi derslerin olması gerektiğini belirtmişlerdir. Ayrıca, öğretmen katılımcıların bir kısmı, okullardaki disiplin sorunları ile mücadelede, Okul Hukuku (n=3), amaç ve hedeflere ulaşmada ortaya çıkabilecek riskleri yönetebilme adına ise Risk Yönetimi $(n=3)$ derslerinin olması gerektiğine vurgu yapmışlardır. Yönetici katılımcılar ise, MTE için teknoloji kullanımının önemine dikkat çekerek, Teknoloji Kullanımı $(n=1)$ dersinin olması gerektiğini belirtmişlerdir. Katılımcıların bazılarının konuya ilişkin görüşleri şunlardır: 
“...Güncel gelişmeleri takip, liderlik, iletişim, okulu tanıma, hukuksal olaylara müdahale vb. dersler olabilir.” (Ö5).

"Mesleki ve Teknik eğitimde en önemli şey yönetici becerisidir bence, birçok yönetici bu kurumları ilkokul, ortaokul veya diğer liseler ile karıştırıyorlar. Oysaki buranın kendine özgü bir yapısı var. Özellikle iletişim ve yönetim alanlarında birikim ister. Bundan dolayı iletişim, liderlik, mesleki eğitimi tanıma, bütçe yönetimi $v b$. konularda beceri sahibi olmalıdirlar." (Ö1)

"Ĕ̈itim; mesleki ve teknik eğitimin işleyişini, amacını, bütçeyi, iletiş̧imi, yönetimi konu alan bir eğitim şeklinde tasarlanmalıdır diye düşünüyorum. Çünkü bir MTE yöneticisi en çok bu konularda zorlanıyor hele birde meslekçi değilse işler daha da kendisi için karmaşık hale gelebiliyor." (Y3)

"Bu eğitim içeriği günün şartlarına ve kişisel ihtiyaçlara göre güncellenebilir ve yıl içerisinde tekrar edebilen uygulamalı eğitimi hedef alan bir yapıya sahip olmalıdır. Özellikle yöneticilerin mesleki ve teknik eğitimin ruhunu anlayan liderler olarak yetişmesine, öğrencilerin kariyer planlamalarında onlara yön verecek bilgiye, iş dünyasında yaşanan hızl gelişmeleri takip ederek, okullarına yansitabilecek değişim yöneticisi olmaya imkân sağlamalıdır." (Y12).

Eğitimin süresi ve eğitim sürecinin değerlendirmesi nasıl olmalıdır? Sorusuna öğretmen ve yönetici katılımcılar, özellikle süre boyutunda derslerin içeriğinin eğitim süresini belirleyeceğine vurgu yaparak $(n=9, n=6)$, eğitimin sürdürülebilirlik özelliğinin olması gerektiği yorumunu yapmışlardır $(n=6, n=4)$. Bunun yanı sıra eğitimin, süre olarak; 10 gün $(n=1)$ ve bir haftalık bir süreyi kapsamasının yeterli olacağını $(n=1)$ ifade eden yöneticilerimizde olmuştur. Eğitimin değerlendirme boyutuyla ilgili olarak öğretmen ve yönetici katılımcılar bir eğitimi en iyi o eğitimden faydalananların değerlendireceği düşüncesiyle değerlendirmenin, paydaşlardan görüş alma $(n=14, n=5)$, performans kriterlerine göre değerlendirme $(n=5, n=2)$ şeklinde olması gerektiğini belirtmişlerdir. Araştırma katılımcılarının bazıları ise eğitimin teorik olarak verildikten sonra uygulamayı izleme, değerlendirme ve sonuçlara bağlı olarak geri dönüt verme $(n=5, n=2)$ şeklinde olması gerektiğini ifade etmişlerdir. Bazı öğretmen ve yönetici katılımcıların eğitimin, süre ve değerlendirme boyutuna ilişkin görüşleri şu şekildedir:

"Çok uzun süren eğitimler bir süre sonra amaçtan sapabiliyor, bundan dolayı on günlük bir eğitim daha önce belirttiğim derslerin anlatılabilmesi için yeterlidir.” (Y10)

"Biz yöneticiler yoğun çalışan insanlarız birde çalıştığınız okul MTE olunca iş yükünüz diğer okul türlerine göre üç dört kat artıyor. Bu sebeple bir haftalık bir eğitim yeterlidir. Belki öğrenilenler süreç içerisinde uygulaması yönünden takip edilebilir.” (Y17)

"Bence eğitimin süresi ders içerikleri ve derslerin işleniş biçimlerini esas olan bir program şeklinde tasarlanmalıdır..." (Y3)

"Hiç bir eğitim değerlendirme boyutu olmazsa kendinden beklenen faydayı sağlamaz en azından bu bizim ülkemizde böyle, bundan dolayı alınan eğitimlerin okullarda ne kadar uygulandığına yönelik gözlem, anket, değerlendirme formları vb. uygulanmalıdır. " (Ö1)

"Ĕ̆itimin değerlendirilmesi performans değerlendirmesi şeklinde olmalıdır. Çünkü ölçülmeyen hiç bir şey iyi demek değildir. Ancak ölçülürse iyi olup olmadiğına karar verebiliriz." (Ö15)

“...İzleme, değerlendirme ve geri dönüt verme şeklinde olmalıdır.” (Ö22) 
Üçüncü alt problemde ilk olarak, yönetici ve öğretmenler ile yapılan görüşmeler sonrasında; katılımcıların eğitimde yer alabilecek derslere yönelik olan görüşleri, orta öğretim yönetmeliği, Singapur hükümetinin mesleki ve teknik eğitim yöneticisi eğitim programı ve 2012 METEK strateji çalışma grubunun "Liderlik ve Finansman" isimli çalıştay sonuçları baz alınarak hazırlanmış teknik liderlik becerilerin geliştirilmesi eğitiminde yer alabilecek derslerin ve ders kazanımlarının uygunluğuna yönelik eğitim yönetimi alan uzmanlarının görüşleri alınmıştır. Görüşme verilerine bağlı olarak, eğitim yönetimi alan uzmanlarının kendilerine sunulan dersler ve kazanımlarına yönelik olumlu görüşler bildirdiği $(n=5)$ sonucuna varılmıştır. Ayrıca araştırmaya katılan uzmanlardan bazıları belirtilen derslerin yanı sıra, MTE'nin yapısına, misyonuna ve oraya giden öğrenci profiline bağlı olarak; "Mesleki ve Teknik Eğitimde Okul Terkleri, Devamsızlık ve Okul İçi Şiddet $(n=1)$, Etkili Takım Çalışması $(n=1)$, Proje Geliştirme $(n=1)$, Program Geliştirme $(n=1)$, İnovasyon $(n=1)$ ve Eğitim Yönetimi $(n=1)$ gibi derslerin de olması gerektiğini belirtmişlerdir. Katılımcıların bazıları görüşlerini şu şekilde belirtmişlerdir:

"Mesleki ve Teknik Eğitim Sistemlerine Genel Bakış" adlı ders kazanımlar yönünden uygudur. Belki dersin adı "Mesleki ve Teknik Eğitime Giriş" olarak değiştirilebilir." (K1)

"Meslek liselerinin birçoğunun döner sermayesi olduğu için bu okul yöneticilerinin bütçeleme konusunda bilgi sahibi olmaları gerekmektedir Bundan dolayı "Mesleki ve Teknik Eğitim Okullarında Bütçe Yönetimi ve Kontrolü” adlı ders eğitimler içerisinde yer almalıdır. Bu ders kazanımlar yönünden uygundur." (K2).

"Öğrencilerin yetenek, beceri ve kişilik özelliklerine uygun olan programlara yönlendirilmesinin yapılmasında yöneticilerin bilinçli olması oldukça önemlidir. Bu bağlamda "Mesleki Gelişim ve Kariyer Danışmanlı̆̆l" adlı ders kazanımlarl yönünden uygundur." (K3)

"Veriye dayall, planlamalar yapabilme her kademe yöneticisinin bilmesi gereken bir konudur. Eğitimde sürdürülebilirliğin sağlanması, yapılan çalışmaların takibi, özellikle meslek liselerinde ögrencinin hem eğitim süreci içerisinde hem de iş hayatına geçtiği süreçteki gelişiminin izlenmesi, sistemin kendini yenilemesi ve geliştirebilmesi için veri toplama ve analiz etme önemlidir. "Veri toplama ve Analiz Yapma" dersi kazanımlar yönünden uygundur." (K4)

"Meslek liselerine gelen ögrenciler tabir yerindeyse bizim ülkemizde maalesef ki kalbur altı olarak değerlendirilen kişiler, profil böyle olunca yöneticiler açısından o ögrencileri sistemde tutma, yaşanacak şiddet olaylarını yönetebilme becerisi ön plana çıkmaktadır. Bu sebeplerden dolayl, mutlaka "Mesleki ve Teknik Eğitimde Okul Terkleri, Devamsızlık ve Okul İçi Şiddet" adlı bir dersin beceri geliştirme eğitiminde yer alması gerektiğini düşünüyorum." (K5)

"Günümüz koşullarının okullarda proje kültürünün oluşturulmasını zorunlu kıldığını düşünüyorum. Mesleki ve teknik eğitim okulları bu konuda daha yaratıcı ve inovatif çalışmalar yapabilme açısından avantajlı okullar bundan dolayı teknik liderlik beceri geliştirme eğitiminde "Proje Geliştirme" adlı bir ders yer almalıdır." (K2).

Üçüncü alt problemde ikinci olarak, teknik liderlik becerilerin geliştirilmesine yönelik yukarıda belirtilen dersleri içerecek bir eğitimin; veriliş şekline, süresine ve kimler tarafından verileceğine ilişkin eğitim yönetimi alan uzmanlarının görüşleri alınmıştır. Katılımcıların görüşleri Tablo 2'de yer almaktadır. 
Tablo 2.

Eğitimin Yapılandırılmasına İlişkin Eğitim Yönetimi Alan Uzmanları Görüşleri

\begin{tabular}{|c|c|c|c|}
\hline Tema & Alt Temalar & Kodlamalar/Alt kodlar & $\mathrm{n}$ \\
\hline \multirow{14}{*}{ 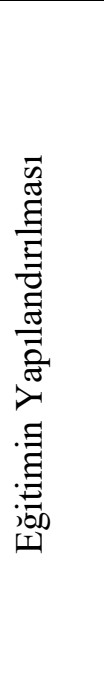 } & & $\checkmark$ Teorik & 5 \\
\hline & 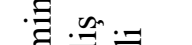 & $\checkmark$ Uygulama & 5 \\
\hline & $\bar{\nabla} \frac{\pi}{0}$ & $\checkmark$ İyi uygulamalar & 1 \\
\hline & & & \\
\hline & & $\checkmark$ Teorik eğitim: & 5 \\
\hline & $\bar{s}$ & $>\quad 3-5$ gün & 2 \\
\hline & : & $>120$ saat & 2 \\
\hline &.$\Xi$ & $>200$ saat & 1 \\
\hline & $\Xi$ & $\checkmark$ Uygulamalı eğitim: & 5 \\
\hline & ion & > Yüksek lisans eğitim süresi kadar & 1 \\
\hline & & $>$ Bir eğitim-öğretim dönemi & 4 \\
\hline & & $\checkmark$ Alan akademisyenleri & 5 \\
\hline & $\Xi 0$ & $\checkmark$ Deneyimli okul müdürleri & 5 \\
\hline & 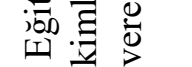 & $\checkmark$ Sektör ve AB uzmanları & 2 \\
\hline
\end{tabular}

Tablo 2. incelendiğinde, araştırmaya katılan eğitim yönetimi alan uzmanlarının tamamı $(n=5)$, eğitimin işleyiş yapısının genişlik ve derinlik olmak üzere iki aşamada tasarlanması gerektiğine vurgu yaparak eğitimlerin teorik $(n=5)$ ve uygulama temelli $(n=5)$ olması gerektiğini belirtmişlerdir. Bunun dışında bir uzman eğitimlerde mesleki ve teknik eğitime yönelik iyi uygulama örneklerinin de incelenmesini ve buna göre bir yapılanmanın olması gerektiğine vurgu yapmıştır.

Araştırmaya katılan uzmanlar eğitim süresinin genel anlamda teorik ve uygulamalı eğitime göre farklılaşacağını ifade ederek, bazı uzmanlar teorik eğitim süresinin 3-5 gün $(n=2)$, 120 saat $(n=2)$ ve 200 saat $(n=1)$ olabileceğini belirtmişlerdir. Araştırmaya katılan bir uzman, uygulamalı eğitimin yüksek lisans eğitim süresi kadar olması gerektiğini belirtirken, bazı katılımcılar ise becerinin davranışa dönüşebilmesi için eğitimin sonuçlarının gözlenmesi gerektiğinden eğitim süresinin en az bir eğitim-öğretim dönemi $(n=4)$ kadar olması gerektiğine vurgu yapmışlardır.

Araştırmaya katılan uzmanların tamamı $(n=5)$ eğitimin; alan akademisyenleri ve deneyimli okul müdürleri tarafından verilmesi gerektiğini belirtirlerken, araştırmaya katılan iki uzman ise, eğitimi verecekler arasında mutlaka mesleki ve teknik eğitimin hitap ettiği sektör ve $\mathrm{AB}$ uzmanlarının da olması gerektiğine vurgu yapmışlardır. Katılımcıların bazıları görüşlerini şu şekilde belirtmişlerdir:

"Hizmet öncesi veya hizmet içi verilen yönetici eğitimleri genel olarak teorik anlatımlı eğitimlerdir. Bundan dolayı hem öğrenenler hem de ögreticiler açısından süreç beklenilen gibi sonuçlanmamakta, oysaki eğitim denildiği zaman teorik ve uygulamalı eğitimin birlikte olduğu ĕgitimler tasarlanmalıdır. Sürede teorik kısmın anlatıldiğı 3-5 günlük eğitimin sonrasında, teorik bilginin davranışa dönüşmesinin gözlenebileceği uygulamalı eğitim olmalıdır. Buda en az bir ĕgitim- ögretim dönemi kadar olmalıdır. Ë̆itim; alan akademisyenleri, alanda iyi uygulamalar yapan yöneticiler, sektör uzmanları ve AB uzmanları kombinasyonunda verilmelidir." (K2)

"Beceri kazandırma eğitimleri teorik ve uygulamalı olarak iki kısımdan oluşmalıdır. Böylesi bir eğitim, 120 saatlik teorik, bir yüksek lisans süresi kadarda uygulamalı eğitimi içermelidir. Bu süreçte okul ziyaretleri yapılmall, teoriğin uygulamaya dönüşmesi yerinde izlenmelidir. Eğitimi verecekler arasında mutlaka sektörden kişiler, alan akademisyenleri, deneyimli okul müdürleri olmalıdır." (K3) 
"Dünyadaki yönetici yetiştirme programlart incelendiğinde eğitimlerin teorik ve uygulamalı olarak verildiği görülmektedir. Ayrıca eğitim sürecinde iyi uygulamalar mutlaka incelenmeli ve neler yapılabileceği konusunda farkındalık kazandırlmalıdır. Ĕ̈itimin teorik kısmı 200 saat, uygulama kısmı ise en az bir eğitim-öğretim süreci kadar olmalıdır. Eğitimi; alan akademisyenleri, iyi uygulamalar yapan yöneticiler ve $A B$ uzmanlart vermeli ki ĕgitimden beklenen fayda sağlanabilsin." (K5)

Bütün bu bulgulardan hareketle, öğretmen, yönetici ve eğitim yönetimi alan uzmanlarından alınan görüşler doğrultusunda Mesleki ve Teknik Anadolu Lisesi yöneticilerinin teknik liderlik becerilerinin geliştirilmesi için ihtiyaç duyulan eğitim; önerilen dersler, süre, değerlendirme ve eğitimi verecekler boyutları bir araya getirilerek Tablo 3'de sunulmuştur.

Tablo 3.

Mesleki ve Teknik Anadolu Liseleri Yöneticilerinin Teknik Liderlik Becerilerinin Geliştirilmesi Eğitimi

\begin{tabular}{|c|c|c|c|}
\hline Önerilen dersler & Süre & Değerlendirme & Eğitimi verecekler \\
\hline $\begin{array}{l}\text { - Mesleki ve Teknik } \\
\text { Eğitime Giriş } \\
\text { - Mesleki ve Teknik } \\
\text { Eğitimde Uygulamalar } \\
\text { - Mesleki Gelişim ve } \\
\text { Kariyer Danışmanlığı } \\
\text { • Mesleki ve Teknik } \\
\text { Eğitimde Liderlik } \\
\text { - Eğitimde Stratejik } \\
\text { Planlama } \\
\text { - Mesleki ve Teknik } \\
\text { Eğitim Okullarında } \\
\text { Bütçe Yönetimi ve } \\
\text { Kontrolü } \\
\text { - Mesleki ve Teknik } \\
\text { Eğitimde Kaynak } \\
\text { Yönetimi } \\
\text { - Eğitimde Örgütsel } \\
\text { Değişim } \\
\text { - Eğitim Örgütlerinde } \\
\text { İletişim } \\
\text { - Eğitimde Veri } \\
\text { toplama ve Analiz } \\
\text { Yöntemleri } \\
\text { • Okullarda Risk } \\
\text { Yönetimi } \\
\text { • Mesleki ve Teknik } \\
\text { Eğitimde Okul } \\
\text { Terkleri, Devamsızlık } \\
\text { ve Okul I̧i Şiddet } \\
\text { • Etkili Takım } \\
\text { Çalışması } \\
\text { - Proje Geliştirme } \\
\text { - Program Geliştirme } \\
\text { - İnovasyon }\end{array}$ & $\begin{array}{l}\text { - Teorik eğitim süresi: } \\
\text { Eğitim-öğretim dönemi } \\
\text { başında verilecek } \\
\text { şekilde } \\
-3-5 \text { gün arası } \\
\text {-120 saat } \\
\text {-200 saat } \\
\text {-10 gün } \\
\text { - Uygulamalı eğitim } \\
\text { süresi: Alınan teorik } \\
\text { eğitimin pratikte } \\
\text { uygulanabilmesi ve } \\
\text { buna bağlı } \\
\text { değerlendirme } \\
\text { yapılabilmesi için; } \\
\text {-Yüksek lisans eğitim } \\
\text { süresi } \\
\text {-En az bir eğitim- } \\
\text { öğretim dönemi } \\
\text { - Bir eğitim-öğretim yılı }\end{array}$ & $\begin{array}{l}\text { Karma } \\
\text { değerlendirme } \\
\text { olarak; } \\
\text { - Teorik eğitimi } \\
\text { veren uzmanların } \\
\text { program } \\
\text { kazanımlarına göre } \\
\text { değerlendirmesi } \\
\text { • Eğitimden fayda } \\
\text { sağlayıcıların } \\
\text { değerlendirmesi } \\
\text { (anketlerle paydaş } \\
\text { değerlendirmesi, } \\
\text { performans } \\
\text { kriterlerine göre } \\
\text { değerlendirme). }\end{array}$ & $\begin{array}{l}\text { Derslerin içeriklerine } \\
\text { göre; } \\
\text { - Alan } \\
\text { akademisyenleri } \\
\text { - Deneyimli okul } \\
\text { müdürleri } \\
\text { - Sektör ve AB } \\
\text { uzmanları }\end{array}$ \\
\hline
\end{tabular}


Tablo 3. incelendiğinde, 3 temel beceri olan; pedagojik ve sosyal becerileri, yönetimsel becerileri ve mesleki becerileri geliştirebilecek derslerin önerilen eğitim içerisinde yer aldı̆̆ 1 görülmektedir. Eğitim süresinin; teorik ve uygulamalı eğitim olarak iki aşamalı olarak, değerlendirme sürecinin ise, teorik eğitimi veren uzmanların program kazanımlarına göre ve eğitimden fayda sağlayıcıların değerlendirmesi şeklinde yapılandırıldığı görülmektedir. Ayrıca böyle bir eğitimin, derslerin içeriklerine göre; alan akademisyenleri, deneyimli okul müdürleri, sektör ve $\mathrm{AB}$ uzmanları işbirliğiyle verilmesi gerektiği görülmektedir.

\section{Tartışma, Sonuç ve Öneriler}

Araştırmanın bulgularına göre, mesleki ve teknik eğitim okulları yöneticilerinin, bu okulların misyonları göz önüne alınarak, teknik liderlik becerilerinin geliştirilmesi için bir eğitime ihtiyaçları olduğu sonucuna ulaşılmıştır. Iş̧k'ın da (2003), belirttiği gibi, müdürlük formasyon programına katılmış bireylerin müdür olarak görev yapacakları okulların tür ve düzeyleri önemli bir boyuttur. Her okul türü ve düzeyine uygun programlar oluşturulmalıdır. Her okulun kendine özgü özellikleri olduğu gibi okulların tür ve düzeylerine göre de aralarında büyük farklılıklar vardır. Bu bağlamda, gelişen yeni teknolojiler ile birlikte iş dünyasının artan rekabet koşulları ve bilgi toplumunun gerektirdiği yeni beceriler, mesleki ve teknik eğitim yöneticilerinin bu becerileri kazanması için eğitimlerini ön plana çıkarmaktadır denebilir. Castetter ve Young (2000), örgütsel amaçların gerçekleştirilmesi için önemli bir süreç olan insan kaynaklarının geliştirilmesinde öncelikle, örgüt çalışanlarının eğitim ihtiyaçlarının belirlenmesi gerektiğini belirtmiştir. Bunu destekler nitelikte, Kesim de (2009), yaşam boyu öğrenme kavramının 21. yüzyılda önem kazanmasıyla birlikte, öğrenme kavramının yeniden yorumlanmaya başlandığına ve daha önce bilinen bazı kavramların günümüz koşulları çerçevesinde yeniden ele alınması gerektiğine vurgu yapmıştır.

MTE yöneticilerinin teknik liderlik becerilerini geliştirmeye yönelik derslere ilişkin bulgulara göre, verilecek bir eğitimin mesleki ve teknik eğitimin amacına uygun olarak; liderlik, iletişim, veri toplama ve analiz yapma, mesleki ve teknik eğitimi tanıma, stratejik plan yapma, bütçe yönetimi, okul hukuku, risk yönetimi, kaynak yönetimi, değişim yönetimi, kariyer danışmanlığı ve zaman yönetimi derslerini içermesi gerektiği sonucuna ulaşılmıştır. Ayrıca öğretmenler eğitimde toplamda 12 ders olması gerektiğini önerirlerken, yöneticiler 11 ders önerisinde bulunmuşlardır. Öğretmenler eğitimin insan odaklı bir sistem olması ve belirlenen eğitimsel hedeflere ulaşmada risk taşıması nedeniyle Okul Hukuku ve Risk Yönetimi derslerinin olması gerektiğine vurgu yapmışlardır. Yöneticiler ise, mesleki ve teknik eğitimin sektörel gelişmelerin gerisinde kalmaması için teknoloji kullanımının önemine dikkat çekerek, Teknoloji Kullanımı dersinin eğitimlerde yer alması gerektiğini belirtmişlerdir. Usdan (2000), çalışmasında geçtiğimiz yüzyılda müdürün rollerini; yasal mevzuatı uygulamak, programı yürütmek, okulun ve personelin ihtiyaçlarını gidermek, bütçeyi dengeli bir şekilde kullanmak, okulu güvenli bir yer haline getirmek ve toplumla ilişkileri sağlıklı bir şekilde yürütmek olarak tasarlandığını belirtmiştir. Bulguyu destekler nitelikte, Young (2007), okul yöneticilerinin hayat boyu öğrenmeyi felsefe edinen bir anlayışla mesleki gelişim içerisinde olmalarının önemine dikkat çekerek, özellikle; öğretimsel liderlik, yönetimsel liderlik, çatışma yönetimi, finansal konular, okul hukuku ve yönetmelikler, zaman yönetimi ve öğretmen mesleki gelişimi noktasındaki rol ve sorumluluklarına vurgu yapmıştır. Benzer olarak, Avrupa Mesleki ve Teknik Eğitim Geliştirme Merkezi (Cedefop, 2009), mesleki ve teknik eğitim müdürlerinin sorumluluklarını; yönetimsel, finansal, insan kaynakları yönetimi, pedagojik liderlik olarak tanımlamıştır. Bu bulgu gösteriyor ki, MTE yöneticilerinin teknik liderlik becerilerinin okulların amaçları göz önüne alınarak iyi tasarlanmış bir eğitimle desteklenmesi gerekmektedir. METEK (2012), projesinde de yöneticilik için sertifika programı olması gerektiği bu programın içerisinde de; personel yönetimi, iletişim, finans yönetimi, kaynak yönetimi, öz değerlendirme temelli kalite güvence, değişim yönetimi, problem çözme, süreç yönetimi, risk yönetimi ve sektörle iletişim ders modüllerinin olmas1 gerektiği belirtilmiştir. Gerek alan yazına, gerekse araştırma bulgularına göre, mesleki ve teknik eğitimdeki müdürlerin; liderlik, teknoloji kullanımı, toplantı yönetimi, raporlama yapabilme, farklı insanlarla iletişim ve etkileşimde bulunma, etkili takım çalışması yapma, stratejiler 
geliştirebilme, finansal yönetim, zayıf ve güçlü yönleri belirlemek için analiz yapma, risk alabilme, ulusal ve yerel dengeleri gözeterek planlamalar yapma, değişimi yönetebilme noktalarında gerekli becerileri kazanmaları gerektiği ifade edilebilir.

Eğitimin süresine yönelik bulgulara göre, sürenin; dersin içeriğine göre belirlenmesi, eğitimi verecek kişilerin süreye karar vermesi, uygulamalı ve teorik olarak düşünüldüğünde, teorik eğitimin 3-5 gün, ya da 200 saat olması, uygulama kısmının ise sonuçlarının ölçülmesi için bir eğitim-öğretim y1lı ya da bir eğitim-öğretim dönemi kadar olması, gerektiği gibi farklı görüşler ortaya çıkmıştır. Bu bulgulara bağlı olarak, eğitimin teorik ve uygulamalı olarak iki bölümden oluşması gerektiği, süreninde teorik bilginin uygulamada kendini gösterecek kadar bir süreci kapsaması gerektiği söylenebilir. Bu bulguya paralel olarak, Balyer ve Gündüz (2011), çalışmalarında, Türkiye' de eğitim yöneticisi yetiştirmeye yönelik teorik ve pratik süreci olan bir eğitim modeli sunmuşlardır. Bu modelde, yönetici adaylarının belirlenen üniversitelerde 2 yıl müdürlük formasyonu eğitimine tabi tutulmalarına ayrıca adayların okulu yönetme, eğitim ve öğretimi planlama, takım çalışmasını organize etme, çatışmayı çözme, iletişim becerilerini geliştirme, personeli geliştirme, araştırma sonuçlarını yorumlama ve değerlendirme, portfolyo hazırlama, okul programlarını yönetme ve okul geliştirme gibi birçok alanda uygulamalı beceriler kazanması gerektiğine vurgu yapılmıştır.

Eğitimin değerlendirilmesine yönelik bulgulara göre, eğitim değerlendirmesinin; paydaş değerlendirmesi, performans değerlendirmesi, izleme, değerlendirme ve geri dönüt verme ve eğitim verenlerin değerlendirmesi şeklinde olması gerektiği sonucuna ulaşılmıştır. Bu bulgulara göre, katılımcıların, okul yöneticilerinin çok yönlü görüşler doğrultusunda kendi güçlü ve zayıf yönlerini görebilecekleri bir değerlendirme sistemini önemsedikleri söylenebilir. Araştırma bulgusunu destekler nitelikte, Can ve Çelikten (2000), araştırmalarında, eğitim yöneticilerinin yetiştirilmesi amacıyla hazırlanacak olan programlardaki ders içeriklerinin örnek uygulamalarla desteklenmesi ve paydaşların görüşleri alınarak değerlendirilmesi gerektiğini vurgulamışlardır.

Eğitim yönetimi alan uzmanlarının, kendilerine sorulan dersler ve ders kazanımlarını uygun buldukları sadece bazı dersler için, dersin ismine yönelik önerilerde bulundukları, eğitimin; alan akademisyenleri, deneyimli okul müdürleri, sektör ve $\mathrm{AB}$ uzmanları tarafindan verilmesi gerektiği kanısında oldukları sonucuna ulaşılmıştır. Bu bulgudan hareketle, eğitim yönetimi alan uzmanlarının mesleki ve teknik eğitim yöneticilerine verilebilecek bir eğitimde mesleki ve teknik eğitimin kendine özgü yapısını göz önüne aldıkları, yönetim sorumluluğunu taşıan MTE yöneticilerinin bu bağlamda yetişmesini destekledikleri şeklinde yorumlanabilir. Zira METEK (2012), proje raporlarında da, genel orta öğretim liderleri ile mesleki ve teknik eğitimde görevli liderler arasında hedef alacakları gruplar açısından farklılıklar olduğundan dolayı yöneticilerin, bir takım farklı liderlik becerilerine sahip olmaları gerektiğine vurgu yapılmıştır. Yine araştırma bulgusunu destekler nitelikte, Özmen ve Kömürlü'nün (2010) yaptığı araştırmada, yönetici yetiştirmede, teorik ve pratiğe dayalı hizmet içi eğitim ve seminerlerin düzenlemesi, mentör müdürler tarafından uygulamalı eğitim yönetimi (staj gibi), MEB-YÖK işbirliğinde hazırlanacak akademik eğitim programları ve liderlik eğitimi gibi eğitimlerin olması gerektiği yönünde görüşler belirtilmiştir.

Genel olarak değerlendirildiğinde, mesleki ve teknik eğitim yöneticilerinin teknik liderlik beceri gelişimlerinin tüm katılımcı gruplar tarafından önemsendiği söylenebilir. Ayrıca tüm okullar gibi mesleki ve teknik eğitim okullarının da amaçları göz önüne alınarak, teknik liderlik becerilerin geliştirilmesine yönelik teorik ve uygulama olacak şekilde iki aşamalı ve çok yönlü değerlendirmeyi içeren bir eğitimin olması gerektiği sonucuna ulaşıldığı söylenebilir. Şentuna’ya (2007) göre, yöneticilik eğitimleri okul tür ve kademesine uygun yöneticilik becerilerini kapsamalıdır. Çünkü bu kapsamda eğitim almamış bir eğitim yöneticisinin okulunda oluşan sıkıntılar sadece öğretmeni, öğrenciyi, eğitim-öğretim niteliğini olumsuz etkilemeyecek dolaylı olarak tüm toplumu olumsuz yönde etkileyecek ve okulun amaçları ile Milli Eğitimin genel amaçları arasında fark oluşmasına neden olacaktır. Araştırma sonuçlarına bağlı olarak;

1. Mesleki ve Teknik Anadolu Liseleri yöneticilerine okullarının var oluş misyonlarına uygun teknik liderlik beceri eğitimlerinin verilmesi, 
2. Mesleki ve Teknik Anadolu Liseleri yöneticilerinin teknik liderlik beceri eğitimlerinin teorik ve uygulamalı olacak şekilde iki aşamalı bir eğitim olarak tasarlanması,

3. Veri zenginliği sağlama adına, araştırmanın çalışma grubu çeşitlendirilerek, farklı paydaş gruplarından (öğrenciler, yardımcı personel, ilgili özel sektör yöneticileri ve sivil toplum kuruluşları, yerel yönetim temsilcileri vb.) görüşler alınarak, MTE yöneticilerinin teknik liderlik becerileri standartlarının oluşturulması önerilebilinir.

\section{Kaynaklar}

Ağaoğlu, E., Altınkurt, Y., Yılmaz, K. ve Karaköse, T. (2012). Okul yöneticilerinin yeterliklerine ilişkin okul yöneticilerinin ve öğretmenlerin görüşleri (Kütahya İli). Eğitim ve Bilim Dergisi, 37(164), 160-175.

Altınkurt, Y. (2007). Ĕ̈itim örgütlerinde stratejik liderlik ve okul müdürlerinin stratejik liderlik uygulamaları (Yayınlanmamış doktora tezi). Anadolu Üniversitesi, Eskişehir.

Anapa, S. (2008). Avrupa birliğine uyum sürecinde Türkiye'de mesleki ve teknik eğitim (Yayınlanmamış yüksek lisans tezi). Marmara Üniversitesi, İstanbul.

Arnn, J. W. ve Mangieri, J. (1988). Effective leadership for effective schools: A survey of principals' attitudes. NASSP Bulletin, 72(505), 1-7. doi./10.1177 \%2F019263658807250502

Austin, G. R. ve Holowenzak, S. P. (1985). An examination of 10 years of research on exemplary schools: Research on exemplary schools. G. R. Austin, H. Garber (Yay. haz.). Orlando: AcademicPress.

Balc1, A. (2001). Etkili okul ve okul geliştirme: kuram, uygulama ve araştırma (Geliştirilmiş ikinci bask1). Ankara: Pegem A Yayınc1lık.

Balyer, A. ve Gündüz, Y. (2011). Değiş̧ik ülkelerde okul müdürlerinin yetiştirilmesi: Türk Eğitim Sistemi için bir model önerisi. Kuramsal Eğitim Bilim Dergisi, 4(2), 182-197.

Buluç, B. (2009). İlköğretim okullarında bürokratik okul yapısı ile okul müdürlerinin liderlik stilleri arasındaki ilişki. Ĕgitim ve Bilim, 34(152), 71-86.

Büyüköztürk, Ş., Çakmak, E. K., Akgün, Ö. E., Karadeniz, Ş. ve Demirel, F. (2013). Bilimsel araştırma yöntemleri. Ankara: Pegem A Yayıncılık.

Can, N. ve Çelikten, M. (2000). Türkiye'de eğitim yöneticilerinin yetiştirilmesi süreci. Milli Eğitim Dergisi, 148. Erişim adresi: http://dhgm.meb.gov.tr/yayimlar/dergiler/ Milli_Eğitim_Dergisi/148/11.htm.

Castetter, William, B., Young ve Phillip. I. (2000). The human resource function in educational administration (Seventh edition). Upper Saddle River, New Jersey: Merrill.

CEDEFOP (2008). A sample of competence frameworks for vet profiles. European Centre for The Development of Vocational Training Publications. Erişim adresi: www.cedefop.europa.eu.

CEDEFOP (2009a). Modernising vocational education and training. European Centre for The Development of Vocational Training Publications. Erişim adresi: www.cedefop.europa.eu.

CEDEFOP (2009b). Competence framework for vet professions: Handbook for practitioners. European Centre for The Development of Vocational Training Publications. Erişim adresi: www.cedefop.europa.eu.

CEDEFOP (2009c). Competence framework for vet professions handbook. European Centre for The Development of Vocational Training Publications. Erişim adresi: www.cedefop.europa.eu.

CEDEFOP (2010). Professional development opportunities for in-company trainers. European Centre for The Development of Vocational Training Publications. Erişim adresi: www.cedefop.europa.eu.

CEDEFOP (2011). Exploring leadership in vocational education and training. European Centre 
for The Development of Vocational Training Publications. Erişim adresi: www.cedefop.europa.eu.

CEDEFOP (2012a). In-company trainers: competence requirements, certification and validation peer learning activity. European Centre for The Development of Vocational Training Publications. Erişim adresi: www.cedefop.europa.eu.

CEDEFOP (2012b). Competence framework for vet professions handbook for practitioners. European Centre for The Development of Vocational Training Publications. Erişim adresi: www.cedefop.europa.eu.

CEDEFOP (2012c). Peer learning activity 'portrait of in-company trainers: Competence requirements, Certification and Validation. European Centre for The Development of Vocational Training Publications. Erişim adresi: www.cedefop.europa.eu.

CEDEFOP (2013). Trainers in Continuing VET: Emerging Competence Profile. European Centre for The Development of Vocational Training Publications. Erişim adresi: www.cedefop.europa.eu.

Coates, H., Meek, L., Fridman, T., Nooman, P. ve Mitchell, J. (2010). VET leadership for the future: Contexs, characteristics and capabilities. Research briefing. doi: 10.1080/0309877X.2012.684042.

Cohen, L., Manion, L. ve Morrison, K. (2003). Research methods in education. NewYork: RoutledgeFalmer.

Daly, A.J. ve Chrispeels, J. (2008). A question of trust: predictive conditions for adaptive and technical leadership in educational contexts. Taylor \& Francis Group, LL, 7(1), 30-63.

Gürbüz, R., Erdem, E. ve Yıldırım, K. (2013). Başarılı okul müdürlerinin özellikleri. Dicle Üniversitesi Ziya Gökalp Eğitim Fakültesi Dergisi, 20, 167-169.

Hsiao, H., Chen, M. ve Yang, H. (2008). Leadership of vocational high school principals in curriculum reform: A case study in Taiwan. International Journal of Educational Development, 28(6), 669-686.

Işık, H. (2003). Okul müdürlerinin yetiştirilmelerinde yeni bir model önerisi. Hacettepe Üniversitesi Ë̆itim Fakültesi Dergisi, 24, 206-211.

Karaçam, F. (1996). İşsizlikle mücadeleye yönelik sosyal politikalarında mesleki eğitimin yeri ve Türkiye'deki önemi (Yayımlanmamış yüksek lisans tezi). Anadolu Üniversitesi, Eskişehir.

Karataş, Z. (2015). Sosyal bilimlerde nitel araştırma yöntemleri. Manevi Değerli Sosyal Hizmet Araştırmaları Dergisi, 1(1), 62-80.

Kesim, E. (2009). Okul yöneticilerinin uzaktan eğitim yoluyla yetiştirilmeleri için eğitim ihtiyaçlarına dayalı bir model önerisi (Yayınlanmamış doktora tezi). Anadolu Üniversitesi, Eskişehir.

Kochamba, D.M. (1996). Principals' and teachers' perceptions of critical leadership skills for elemantary principals (Yayınlanmamış doktora tezi). South Carolina State University, Orangeburg, South Carolina,

Levine, D. U. ve Lezotte, L. W. (1990). Unusually effective schools: a review and analysis of research and practice. UW-Madison: The National Center for Effective Schools. Erişim adresi: https://search.library.wisc.edu/catalog/999690759302121.

Maxwell, J. C. ve Covey, S. R. (2007). The 21 trrefutable laws of leadership: follow them and people will follow you (10th Anniversary Edition). USD: Thomas Nelson Publisher.

Meadows, J. M. (2007). Leadership skills believed to enhance and expand the leadership capacity and sustainability of future private school administrators (Yayınlanmamış doktora tezi). University of La Verne, La Verne, California.

MEB (2013). 2013-2017 Mesleki ve Teknik Eğitim Strateji Belgesi ve Eylem Planı (Taslak). Erişim adresi: http://www.kso.org.tr/duyurures/mesleki-ve-teknik-eğitim-stratejibelgesi-ve-eylem-plani-taslaği.pdf.

METEK (2012). Liderlik ve finansman. Mesleki ve Teknik Ĕgitimin Kalitesinin Gelişstirilmesi Projesi Strateji Çalışma Grubu Çalıştay Raporu, Ankara. Erişim adresi: metek.meb.gov.tr. 
Miles, M, B. ve Huberman, A. M. (1994). Qualitative data analysis: An expanded sourcebook. (2nd ed). Thousand Oaks, CA: Sage.

NCVER (2001). The Changing role of staff development for teachers and trainers in vocational education and training. National Centre for Vocational Education Research Publications. Erişim adresi: www.ncver.edu.au.

NCVER (2003a). Leadership in vocational education and training. National Centre for Vocational Education Research Publications. Erişim adresi: www.ncver.edu.au.

NCVER (2003b). Quality indicators in vocational education and training. National Centre for Vocational Education Research Publications. Erişim adresi: www.ncver.edu.au.

NCVER (2007). Approaches for sustaining and building management and leadership capability in vet providers. National Centre for Vocational Education Research Publications. Erişim adresi: www.ncver.edu.au.

NCVER (2012). Financial data on public vocational education and training. National Centre for Vocational Education Research Publications. Erişim adresi: www.ncver.edu.au.

Özdemir, G. (2015). Mesleki ve teknik ortaöğretim okullarl yöneticilerinin teknik liderlik becerilerinin belirlenmesi ve gelişstirilmesi (Yayınlanmamış doktora tezi). Gaziantep Üniversitesi, Gaziantep.

Özmen, F. ve Kömürlü, F. (2010). Eğitim örgütlerine yönetici seçme ve atamada yaşanan zorluklar ve yönetici görüşleri temelinde çözüm önerileri. Sosyal ve Beşeri Bilimler Dergisi, 2(1), 25-32.

Sadıkoğlu, P. (2007). Endüstri meslek lisesi yöneticilerinin problem çözme becerileri (Yayınlanmamış yüksek lisans tezi). Beykent Üniversitesi, İstanbul.

Şentuna, A. (2007). Değişen liderlik rolleri perspektifinde okul yöneticilerinin öğretmen performansını yönetmesi (Yayınlanmamış yüksek lisans tezi). Yeditepe Üniversitesi, İstanbul.

Usdan, M. (2000). Leadership for student learning: Reinventing the principalship, Institute For Educational Leadership, 1, 24.

Ünlüeser, S. T. (2007). Mesleki ve teknik eğitimin gelişimi ve teknik öğretmen yetiştirmede karşılaşılan zorluklar (Yayınlanmamış yüksek lisans tezi). Yeditepe Üniversitesi, İstanbul.

Yıldırım, A. ve Şimşek, H. (2013). Sosyal bilimlerde nitel araştırma yöntemleri. Ankara: Seçkin Yayincilik.

Young, M. (2007). Implications and reccommendations, changing role of the middle level and high school leader: Learning from the past- preparing for the future. National Association of Secondary School Principials one of the Report's Recommendations, 31-58.

\section{Extended Abstract}

\section{Introduction}

Vocational and technical education is vital in terms of providing the individuals with the professional knowledge and the skills required by the country in order to ensure sustainable economic and social development and to increase competitiveness. Vocational and technical education is a problematique of education which has been under discussion for a long while but the intended outcomes have not been reached, yet. Vocational and technical education is among the most indispensable elements of a country's education system for individual, socio-cultural and national requirements. The rapid developments in technological fields and the increase in the share of the service sector in the economy along with the globalization have led to radical changes in the skills that the workforce should possess while increasing the demand for the workforce capable of meeting the sectoral needs. In order to increase the quality of the workforce and to create flexible structures that can meet the requirements of the information society, wellorganized vocational and technical educational institutions are needed in the implementation phase of the system. As the task of raising qualified manpower to support the competitive 
economy required by the countries is primarily the function of vocational and technical educational institutions, it can be claimed that the principals of these institutions should have different skills rather than those of other educational institutions. In order to be successful, vocational and technical education school leaders should not only focus on increasing the academic achievement of students, but also undertake significant tasks such as increasing the effectiveness of the educational environment, providing essential hardware resources to support skill development, promoting teachers in preparing for the lessons, cooperating with all the stakeholders to establish a healthy communication within the school and creating a suitable environment for the development of the students' learning skills. All these highlight the leadership qualities of the administrators at vocational and technical education. In other words, it is clear that the vocational and technical education principals should have technical leadership competencies both in terms of the technical aspect of their work and working effectively with all internal and external stakeholders. In addition, research on the competencies of vocational and technical education principals (Ağaoğlu, 2012; Sadıkoğlu, 2007; Altınkurt, 2007; Cedefop, 2008, 2009, 2010, 2011, 2012, 2013; NCVER, 2001, 2003, 2007, 2012) reveal that their anticipated level of competence is low. For this reason, it is becoming more and more important to improve the technical skills of these school principals and the attempts in this vein to meet the expectations of the staff, students and other stakeholders of the school by increasing the quality in vocational and technical education. In this regard, the aim of this study was to determine whether it is a requirement to create a training program for the technical leadership skills of the principals working at Vocational and Technical Anatolian High Schools, and how such a training program should be structured if it is needed.

\section{Method}

It is a qualitative study. The working group of the study is composed of vocational and technical education schools in Şahinbey and Şehitkamil districts of Gaziantep and the experts in the field of educational administration. The participants were determined using maximum diversity and criterion sampling methods. The study group consisted of 30 teachers, 18 school principals / assistant principals and 5 faculty members ( 3 professors, 2 associate professors). Research data were collected through two different semi-structured interview forms. The first one was prepared to determine the views of teachers and administrators, and the second for the experts in the field of educational administration. In data analysis, content analysis method was used. Initially, codes were formed depending on the interrelating concepts after transferring the obtained data to Atlas.ti qualitative data analysis program, and then each code was placed under the themes and subthemes determined by the researchers based on the interview questions.

\section{Result and Discussion}

The majority of the principals and teachers stated that the administrators needed a training program for the development of technical leadership skills in order to achieve sustainable development in vocational and technical education $(n=27, n=16)$, and very few of them opined contrarily $(n=3, n=2)$. Both groups of participants declared that there should be a technical leadership skill training aimed at quality and success in vocational and technical education in response to the question of Which courses should be included in the training? Highlighting the importance of leadership, participants have suggested the courses such as Leadership $(n=11, n=5)$, Communication $(n=11, n=7)$, Data collection and Analysis $(n=7, n=2)$, The Knowledge of Vocational and Technical Education $(n=6, n=6)$ Strategic Planning $(n=6, n=2)$, Budget Management $(n=3, n=2)$, Resource Management $(n=2, n=1)$, Change Management $(n=2, n=1)$, Career Counseling $(n=2, n=3)$, Time Management $(n=1, n=2)$. Exclusively in the sub-dimension of process, teacher and principal participants emphasized that the content of courses will determine the process of education $(n=9, n=6)$, and that a training program should be sustainable $(n=6, n=4)$ in response to the question of How should the duration and the assessment of the training process be? Regarding the sub-dimension of evaluation of education, teacher and administrator participants remarked that the training program should be evaluated by the 
stakeholders $(n=14, n=5)$ and according to the performance criteria $(n=5, n=2)$ based on the idea that those who indirectly benefit from the program would evaluate it in the best way.

The experts in the field of educational administration mostly found appropriate the learning outcomes of the courses they have been asked for. All of the experts $(n=5)$ indicated that the training program should be theoretical $(n=5)$ and practice based $(n=5)$ by emphasizing that the operational structure of program should be designed in two stages as width and depth.

According to the research findings, it was concluded that the principals of vocational and technical education schools need a training program in order to develop their technical leadership skills considering the missions of these schools. As denoted by Iş1k (2003: 210), the types and levels of the schools in which the individuals who participated in the initial school principal training program will serve as principal require attention. Programs should be created by different school types and levels. As each school has its own characteristics, there are huge differences among the schools according to their types and levels. In this context, it is possible to assert that the growing competition conditions of the business world together with the development of new technologies and the new skills required by the information society necessitate training programs for vocational and technical education principals to acquire these skills. All in all, it can be alleged that technical leadership skill development of vocational and technical education principals is considered important by all participating groups. In addition, it can be concluded that there should be a two-stage training program - theoretical and practical - with multi-faceted assessment to develop technical leadership skills considering the objectives of vocational and technical educational institutions like all the other schools. 